\title{
Loss of Life Purpose as a Problem of Modern Society
}

\author{
Irina Ponizovkina \\ Department of Philosophy \\ Plekhanov Russian University of Economics \\ Moscow, Russia \\ E-mail: irina-ponizovkin@mail.ru
}

\author{
Elena Agibalova \\ Department of Foreign Languages \\ Plekhanov Russian University of Economics \\ Moscow, Russia \\ E-mail: elenagib@rambler.ru
}

\begin{abstract}
The article is dedicated to the eternal philosophical question of life purpose and its development. Particular attention is paid to the loss of life-purpose guidelines which is a relevant problem in a modern Russian society. The reasons for the loss of life purpose are revealed and solutions to this problem are suggested.
\end{abstract}

Keywords-life purpose; life objective; life-purpose guidelines; loss of life purpose; development of life purpose

\section{INTRODUCTION}

The purpose of life is one of the basic eternal philosophical questions and has a long philosophical tradition. A human is a not only a biological but a sociospiritual being who is able to understand the impermanence of his existence in the social space and seeks to understand his mission and place in the world. Who am I? Why did I come into this world? What is the purpose of my life? Why should I live? These questions agitate a person and encourage his development, determine his life stance and foster self-actualization. Thus, the purpose of life is the supreme mean of self-fulfillment and self-realization of a human being.

With the help of a developed life purpose a subject interprets everything that is happening around by determining personal meaning (meaning-for-me). It helps to develop a sustainable sense bearing worldview, makes it integral and reasonable. The purpose of life in this case becomes the basis for the human existence transforming the world instability into a well-constructed building of necessary connections and relations which becomes a space for individual's purposeful activities.

That is why an individual is sensitive about the loss of life purpose. This loss is dramatic for a person as he is losing clear guidelines in a constantly changing reality. Statistics in the end of the 20th century says that the second most widespread cause of death after road accidents is suicide. Sixty students from Idaho University were questioned after their failed suicide attempts and $85 \%$ of them answered that the reason for it was the loss of life purpose, considering that $93 \%$ of them were physically and psychologically fit and had no serious financial difficulties [https://books.google.ru/books?isbn=5885039070].

Durkheim [1] in his famous sociological studies called Suicide proved that the main reason for suicides in highly developed countries is not poverty or hardships but system failures in life guidelines-loss of life purpose. The wise Socrates was right when he warned us two thousand years ago: "The unexamined life is not worth living" [6, p.92]. Many people seek money, glory or pleasures but once they have them, they do not feel satisfied, do not know what to do with them and think that they have wasted their life. Before getting down to any serious business Socrates recommended settling the sense-making issues in order not to have any regrets later.

It is necessary to understand that person's life purpose perceptions reflect to a certain extent the perceptions and values of a certain era, i.e. they have a historical character. The problem of life purpose is particularly relevant during the time of change, crises and in contemporary history when, according to F.Emery, "the ground is dropping out from under you". In a modern "runaway world" (A.Giddens) lifepurpose guidelines are also often running away.

Researchers today (philosophers, sociologists, physicians, etc.) and ordinary people often speak about a "loss of life purpose" in a modern Russian society which is believed to be the reason for general dissatisfaction with your life and deviant forms of life problem solutions - drug and alcohol use - and, finally, a big number of suicides among people of different age categories and socio-financial standing. According to the World Health Organization, Russia in the middle of $90 \mathrm{~s}$ - in the most difficult and watershed years of the contemporary history-was one of the world leaders in the number of suicides. Most often suicides were committed by $45-55$ year old men and young people. While recovering from the economic and the spiritual crisis, Russia moved in 2013 from the second to the fourteenth place in terms of suicide frequency and in 2016 it occupied the thirtieth place [http://www.euro.who.int/_data/assets/pdf_file/0008/25760 6/9789241564779_ru.pdf].

The purpose of life is a dubious notion. It's imperative character, on the one hand, is revealed in personal functioning and is an important element of a subject's abundant life and, on the other hand, is based on general public recognition and social importance. Human lifepurpose guidelines presuppose a strong connection between an individual meaning and a universal one, without mutual merger and coercion. Thus, the loss and search of life purpose can also been considered from two anglespersonally accepted and objectively important values. 


\section{CASE STUdy}

During the whole period of philosophical development the problem of life purpose was addressed by many foreign and Russian researchers, both ancient and contemporary ones, working in different spheres. The purpose of life question is the problem common for the oriental and western philosophical thoughts as it is equally interesting for both of them. The life-purpose problematics makes a basic and integral structure of the whole worldview system of any human culture as well as the process of individual selfdetermination.

Ancient philosophy which was generally cosmocentric connected the purpose of life with the notions of duty and well-being. A personality was the embodiment of Logos manifested in social conventions and the synonym of a social role and status. The problems of life purpose and human life mission were addressed by Aristotle, Plato, Epicurus, Seneca, Marcus Aurelius, etc.

Christianity brought about a brand new interpretation of human identity. It acquired a certain self-value independent from cosmologic aspects as it was an imprint of the Creator's absolute personality. In medieval religious thought the purpose of life generally meant the pursuance of a holy ideal and the finding of the Holy Spirit. Such philosophers as Blessed Augustine and Thomas Aquinas should be mentioned in this connection.

In comparison with the theocentric Middle Ages, the Renaissance philosophy (Leonardo, M.Montaigne, T.More, T.Campanella, etc.) saw anthropocentrism as a specific type of philosophical worldview praising human creativity, helping to change the world and making a human subordinate to God. The value of personality and its supreme mission were revealed. It stands to reason that the great creative minds (Leonardo, Michelangelo, Raphael) appeared at this time.

Philosophers of the Modern Age abandoned religious orthodoxy and started seeking the purpose of life in the world of abstract ideas and in the cognitive sphere (for example, F.Bacon, E.Descartes, B.Spinoza).

In the classical German philosophy a human was studied as a spiritual being, the creator of history, the world of culture, science and morals (I.Kant, J.Fichte, J.Herder, G.Hegel).

Classical Marxism gave way to the so-called activity approach to the understanding of a person and considered a human in terms of all the social relations and the human history. The unity of opposites - personal and public - their degree, changing in different socio-economic formations, according to Marx, determines the meaning of a human life and its value.

Philosophers of the XIX - the beginning of the XX centuries studied human nature by bringing down its essence to the rational origin in some cases and in other cases - to the irrational one. The understanding of life purpose was the subject of many theories and concepts such as the philosophy of life, personalism, pragmatism, existentialism, etc. The works of foreign existentialists of the XX century-M.Buber, A.Camus, S.Kierkegaard, J-P. Sartre, M.Heidegger, L.Shestov, K.Jaspers, etc.- -who addressed the issue of a person's life-purpose choice are of particular importance. Existentialists came to the conclusion that due to the absurdity of the world our life does not apriori have sense and a person has to create his own values in the indifferent world.

Among Russian thinkers the problem of life purpose was addressed by F.Dostoyevsky and L.Tolstoy. Life-purpose problem (as a spiritual-moral and personal problem) was widely studied by Russian philosophers in the end of the XIX - the beginning of the XX centuries: N.Berdyaev, V.Rozanov, S.Solovyov, E.Trubetskoy, S.Frank, etc.

The works of many Russian thinkers, speculating about the purpose of life, had a religious character. L.Tolstoy managed to express the solution to the life purpose problem from a religious point of view: "The essence of any faith consists in giving a meaning to life that will not perish with death".

In the Soviet time the subject of life purpose was rather common and had a pronounced regulatory-educative and worldview character. The real life purpose was seen by Soviet researchers in contributing to the solution of social development challenges, in constructive labor in the course of which prerequisites for multilateral development of personality are formed.

S.Rubinstein gave a detailed characteristic of different historical concepts of life purpose [5]. It is worth noticing that in the framework of these concepts the problem of life purpose loss is not studied deeply but rather formally. As a rule, they examine the importance of life purpose loss for person's activities and its consequences. This subject is more often developed in psychiatrics which focuses on clinical implications and the condition of a person who feels the meaninglessness of his life. As a result, this person is offered dedicated medical aid which basically cannot solve the problem and eradicate its reasons. Nevertheless, the work of the psychiatrist V.Frankl "Man's Search for Meaning" in which the author excels at generalization is worth mentioning.

In order to understand how to overcome the tragedy of life-purpose guidelines loss today, it is necessary to study the conditions and the reasons for the development of personal life purpose.

\section{CONDITIONS FOR THE DEVELOPMENT OF LIFE PURPOSE}

Being an extremely personal phenomenon, life purpose in matter is something suprapersonal connecting it with a superindividual, social system. The more traditional society is and the more people follow deeply-rooted traditions, the easier it is to settle the life purpose issue. Life purpose is personal integration of the system of values functioning in society. The development of civilization, the sophistication of a human society and a human himself result in the creation of an expanding and differentiating world of values 
as well as the complication of connections among them and axiological connections among people.

On the other hand, in order to develop life purpose a certain level of consciousness is required. Pursuance of selfactualization, awareness of your potential opportunities, critical analysis of your capabilities gives sense to a person's life and activity, becomes a basis for self-improvement and self-fulfillment of a human. The need to find life purpose appears not just as a wish to find justification but as a wish to achieve something. It is a need to understand something innermost in order to advance.

Poorness and immaturity of a person's axiological sphere manifests itself in the absence of understanding (or a wish to understand) common human and personal needs, in vague perceptions of long-term life objectives or their compliance with reality. It leads to an undeveloped ideal and, consequently, the absence of the elevated frame of mind.

The process of life-purpose guidelines of a person can be explained with a scheme. "Fig. 1"

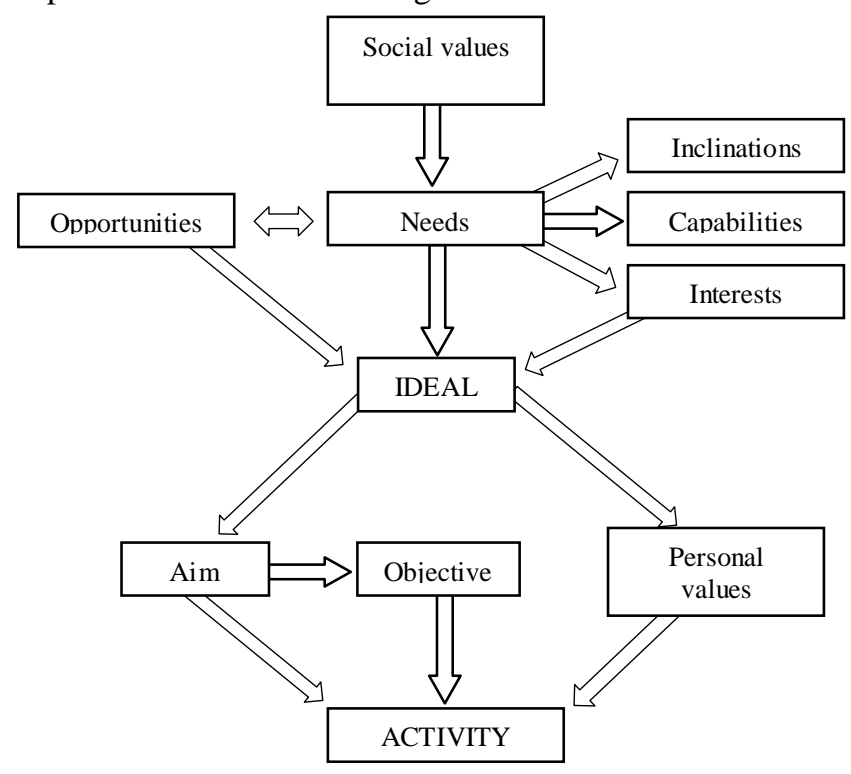

Fig. 1. The process of life-purpose guidelines

If there are "white gaps" or mismatches in this formula's elements and their interconnections, a personal invisible or acute conflict in terms of life purpose is triggered. Its utmost manifestation in a mental state is depression and frustration of needs.

There are several reasons for the loss or non-developed character of life purpose. Let us study them in more detail.

\section{REASONS FOR THE LOSS OF LIFE PURPOSE AND SOLUTION TO THE PROBLEM}

First of all, a person does see a purpose in life or loses it when his ideals are not developed (as mentioned above) or are destroyed due to circumstances. "No wind favors he who has no destined port", said Montaigne. "If you have ideals, you feel the actual direction of your life and favorable winds inevitably bring your boat to the desired coast. The higher the ideal, the stronger the wind...", agrees with the great thinker P.Weinzweig, the founder and president of the International Association "Peace Through Culture" named after N.Roerich [7].

The utilitarian society today more and more often calls on young people to live for the day, achieve quick results, act in the "accessible zone". Our mind is massively attacked by numerous youth magazines with their advice for all occasions (how to maintain your image, how to deal with your boss, what to wear on a date, etc.) and the advertisement of different unimportant stuff claimed to be life-critical for us. With such accentuation a young person (or not a young one which is more tragic) may not see the "forest" for the "trees standing close by" and at a certain life stage will suddenly feel the meaninglessness of numerous "projects" and constant changing of jobs in different "companies", sadness of owning "necessary" things and people and finally the impossibility to assess your life journey. The difficulty in choosing the criteria for such evaluation and the problem of life-purpose guidelines depend directly on the development of person's ideals. It is the presence of ideals that allows assessing life correctly at its every stage, not having any regrets about the journey you have undertaken but rather feeling zest for life.

A story of the famous English architect Christopher Wren is worth mentioning in this case. When supervising the construction of a cathedral built according to his project in London, he decided to find out what was the motivation of hard working ordinary constructors. The architect asked the constructors only one question: "What are you doing?" but received different answers. One of them said without thinking: "What do you mean? I lay bricks..." Another one sadly replied: "I earn my living..." The answer of the third one pleased the architect most: "I help building a magnificent cathedral..." It can be supposed that it was this constructor who derived most satisfaction and joy from his work by creating beauty for others and he would never regret the days he had spent at this construction site.

Genuine ideals today are more and more often substituted by mass media and mass culture with idols and icons-mock substitutes for a mass consumer of life.

In Russian society today the development of ideas guiding and inspiring a person, helping him to rise above prose and the little nothings of life is first of all impeded by the non-developed life purpose of society in general, the absence of a clear social idea which should "possess the masses". The old ideology crashed burying underneath the ideals of the whole generation, not giving any worthy substitute, pushing into the background universal human values. New "heroes of our time" (gangsters, party goers, shady moguls romanticized by the new art) who hardly deserve to be called heroes have entered the history stage. A person faces a conflict between the way he feels and the new requirements set forth by society. It provokes the identity crisis that cannot be overcome and is aggravated by the person's attempt to find life purpose not in a real but in a virtual world. 
The question of life formulated by E.Fromm "To have or to be?" [3] has become extremely relevant in our time being oriented towards market economy. E.Fromm thought that the reasons for the social crisis in the second half of the 20th century that led to almost devastating state of modern civilization lie in the specific character of the industrial society with its focus on values of acquisition and generation of profit. Such socio-economic system is guided in its development not by genuine human interests but by system requirements which forms a person adapted to them and having a life-purpose paradigm "To have!" In Russian society today this mode of "having" when the approach to life is expressed in a striving to make it your possession and to make everything and everyone your possession as well, dominates in Russian society and is considered the most natural way of existence. The image of a contemporary consumer living with a motto: "I am what I possess and what I consume" described by Fromm is so recognizable in Russian society. In such conditions of material values and guidelines absolute domination a person oriented towards a different mode of human existence-“To be!" (creative, socially active, self-fulfilling Personality interested in the world, surpassing the borders of his own isolated ego) - is lost, cannot find his place in life, feels unwanted and uninteresting. The person's ideals are crashed against the unsurpassable wall of social values.

A person can also face an internal conflict if a life purpose alien to him but acceptable due to certain circumstances is imposed from the outside. It is an invisible or "voluntary" forced substitution of your own ideal. A common reason for such internal conflict are the nearest ones: in dynasty families a child often has no choice regarding his future (inherit a business, continue the dynasty of physicians, actors, etc.); parents wishing all the best to their child prepare him to the most "conformist" job for which the child is showing no inclinations; a wife madly in love with her husband agrees to become a housewife for the sake of his family ideals...In a number of cases sad circumstances are decisive: a woman dedicates her life to taking care of her sick mother or a child... Newspapers and magazines, TV programs, memoirs and fiction abound in such stories.

At first sight it seems surprising that in these cases not only the person's nearest ones but very often he himself derives satisfaction from life. It is to a great extent accounted for by the support and assessment by relatives and dear people, feeling of fulfilment and partial self-fulfillment as a personality. But why these stories are accompanied by sad intonations and certain innuendo? It happens because the sense of satisfaction, even a deep one, cannot substitute happiness...It is happiness that is the indicator and the consequence of life purpose fulfillment.

The search of purpose in life is a complicated, strictly individual work, if not to say intimate, intolerant to any coercion and sometimes even advice. A person can have multiple options (professional activity, family, spiritual or public activity, creative work, striving to "have", etc.) and it is important not to make a mistake, to find your own main road of life which will be a pleasure to walk along. It is on this road that a person can fulfill his potential, express his inclinations and interests, develop skills, satisfy the existing needs, feel genuine enthusiasm and inspiration, discover yourself and present yourself to the world becoming its integral part.

The option selected by a person is the main one determining the life strategy but, as a rule, not the only one. And there is no point in depriving yourself of the joy of ample existence by ignoring other life spheres and by aiming all your activities only at one selected objective. A person is a creature seeking comprehensive existence. And happiness is a reward for multilateral self-fulfillment. It is for a reason that the formula of happiness that was accidentally overheard by N.Hikmet from a simple woman: "Happiness is when in the morning you want to go to work and in the evening you want to go home" has become eternal.

Life-purpose guidelines have to be voluntary accepted not only by the soul but also by mind. Otherwise at a certain stage of moving towards the ideal it can result in a personal tragedy when it turns out that the life objective does not comply with person's opportunities - subjective or objective ones. Wasted efforts and time, lost illusions and disappointments make a person unhappy, frustrate him and lead to internal sufferings. It is not a problem if it is a young person who faces this issue: spiritual quests will only make him stronger and will show the right road which he is able to deal with. And if a person is in the middle of his life journey? Frustration of life purpose among mature people is so serious that it results in a loss of self-confidence and self-belief, desperation, loss of interest in life and even suicidal thoughts. Such tragedies in the post-perestroika Russia were quiet common.

The reason for the above mentioned internal conflicts is, on the one hand, stricter and tougher requirements imposed by society on a contemporary person amid high competition and an accelerated pace of life and, on the other hand, a trend in modern pedagogy (starting from pre-school years) of developing inflated self-esteem. Numerous Western selfhypnosis methods teach us from the kindergarten: "I am the best!"- and lead to pathologically disturbed literal perception of your ego, lower self-criticism, higher "achievement benchmark", absence of incentives for deep self-actualization and self-development which are substituted with pushiness and aggressiveness in the achievement of goals. And it is not always sufficient in order to fulfill a strategically important life program.

However, it should not mean lack of self-confidence, constant doubts and fears, pessimistic and cynical approach to life which is a sign that a person has low self-esteem and complexes that will certainly be an insurmountable obstacle on the way to ideal and happiness. Favorable wind accompanies the one who has strong personality. Know yourself, ancient people used to say, know your strengths and weaknesses, try to turn your weak points into strong points, scrutinize yourself through other people, self-improve by overcoming the thresholds of your limitations. Rise above yourself but do not lose sight of yourself! - it should be a motto for those who want to turn their ideals and their life purpose into reality. 
The famous English writer Somerset Maugham was physically weak since childhood, often severely ill, his mother died when he was young and he was extremely lonely. But it is these tragic events that helped him to get on the path of spiritual quest, search of life purpose and predetermined the choice of his future profession. Somerset eventually understood that stammering will prevent him from becoming a lawyer like his father. However, it only strengthened his desire to express himself by becoming a writer, to help people in some other way, to share with others his feelings and observations derived from his unfortunate childhood. Attentive contemplation of life and reflections about it gave him abundant material for his future literary pieces which made him immortal. Maugham's destiny is an example of serious internal work of unlocking your potential on the way to your ideal.

Another reason for an internal conflict due to the loss of life purpose is often the confusion of similar notions-life purpose and life objective. This problem seems to be purely theoretical only at first sight. Life purpose is a rather abstract life perspective (the ideal is always somehow vague and general which allows safely adjusting it in the course of life), it is a strategic program of human existence which gives him integrity and loftiness. Life objective is more specific and is subordinate to life purpose and the arising circumstances. If a person does not understand that, the necessity to change the objective, often due to the change in certain conditions, is seen by him as a frustration of life purpose, defeat of your innermost hopes and is endured rather painfully, even tragically. Favorite actors who disappeared from TV screens during the cinema crisis in Russia in the 90s, who found themselves without a job and had to change professional activity in order to earn their living treated this situation differently. Those who understood that temporary change in life objective does not mean losing life purpose or betraying it managed to deal with this difficult situation with least spiritual and physical sufferings. Many people managed to spend this time on gaining additional life experience, selfimprovement, getting new impressions and feelings which laid a good foundation for further professional growth and self-fulfillment. The destiny of those who did not see a difference between the objective and the purpose of life is regrettable and becomes a good lesson: sometimes it is necessary to change your life objective in order not to change its purpose. The achievement of relevant objectives, solution of certain situational challenges at a certain stage, even those that seem quite far from fulfilling the life purpose, sometimes do not move the person away from the highway of his life but instead accelerate his advancement.

Examples from history are rather instructive in terms of life objective and life purpose interrelation. The famous Russian painter Arkhip Kuindzhi was born in a family of a simple shoemaker and used to work as a shepherd boy when he was young. But when Arkhip discovered his talent for drawing he could no longer think of anything else. He was obsessed with a desire to learn how to draw paintings "properly" in order to become a painter. His dream was to be admitted to the Imperial Academy of Arts. He tried to enter it three times and all the three times he failed. The last time twenty nine applicants were admitted and only Kuindzhi was refused. His relatives and friends tried to talk him out of this worthless idea. He seemed to abandon his dream himself and did not make the fourth attempt. Nevertheless he continued mastering the art of painting himself, was drawing all the time and got acquainted with artists and their works. Once he presented his landscape painting at an academic exhibition in Saint Petersburg and unexpectedly received two honorary awards. That is how he was admitted to the academy, and then he became a professor and a famous painter. He used to say to his students: "Neither the sun nor the frost can defeat your spirit...If you have something to say to this world, you will deliver this message regardless of any difficulties and misfortune..."

These words are relevant in today's society as well, when values and ideals are constantly reconsidered and bump and grind of everyday life prevent you from seeing the essential.

\section{CONCLUSION}

As we can see, life purpose is accomplished at two interconnected levels: macro level (sociocultural purposes) and micro level (personal purposes). At the same time the aggregate of life-purpose guidelines is a checks and balances system to external and internal influences and manifests the level of personal development and self-actualization. Disharmony of the individual and the social in a certain person becomes the reason for the loss of life purpose and abundant life.

"Existential vacuum" most often occurs during crises and turbulent changes which was well described by the Russian writer A.Gorky: "As it always happens after social disasters, people tired from humiliating shocks from outside, will be obliged and forced to look into their internal world and think once again about the objective and the purpose of life" [4, p.135]. Although life purpose is an existential notion, it becomes a necessary element of a person, contributing to his survival as a biological species.

The search and fulfillment of life purpose is one of the main needs of a person and its absence is an individual life tragedy. However, as we can see, the loss of life-purpose benchmarks is often illusive and can be overcome. "Powerseeking" pointless everyday fuss is forceless against a person's desire to possess it by finding the purpose of life.

\section{REFERENCES}

[1] Durkheim, E., "Suicide: A Study in Sociology", Glencoe, Illinois: The Free Press, 1951, 405 p.

[2] Frankl, V., "Man's Search for Meaning”, Boston: Beacon Press, 2006, $165 \mathrm{p}$.

[3] Fromm, E., “To Have or To Be?", London, New York: Continuum, 2008, 203 p.

[4] Literary legacy, Tom 70: "Gorky and Soviet writers": Unpublished correspondence, Moscow: publishing house of the Academy of Sciences of the USSR, 1963, $703 \mathrm{p}$.

[5] Rubinstein, M. M., "On the meaning of life", In 2 parts, Part 1: Historical and critical essays, Leningrad, 1927, 198 p.

[6] Plato, Works in 4 t., T. 1, Moscow: Thought, 1986, 810 p. 
[7] Weinzweig, P., "The Ten Commandments of Personal Power", Montreal: Meridian Press, 1988, 208 p. 